\title{
Chest $x$ ray films from construction workers: International Labour Office (ILO 1980) classification compared with routine readings
}

\author{
M Albin, G Engholm, K Fröström, S Kheddache, S Larsson, L Swantesson
}

\begin{abstract}
The extent of agreement between International Labour Office (ILO) and clinical readings of chest $x$ ray films from construction workers was studied. From a survey of 5898 workers 258 subjects with a profusion of small opacities of $\geqslant 1 / 1$ and a stratified sample of subjects with profusion $<1 / 1$ were selected. Only $41 \%$ of the films classified as ILO profusion category $\geqslant 1 / 1$ were clinically recorded as nonnormal for the parenchyma. The proportion of films recorded as pneumoconiotic (or possibly so) was especially low for irregular opacities $(22 \%)$, but increased with the profusion category (both rounded and irregular) as well as with the size of rounded opacities (p 3/11, q $12 / 25, r 3 / 4)$. Only with the profusion category $\geqslant 2 / 1$ were most of the films recorded as pneumoconiotic. The specificity and sensitivity were highest in the geographical areas where a few clinical readers had assessed many films each. The proportion of false negative clinical reports was low for circumscribed pleural thickening of the chest wall ( $9 \%$ ) and diaphragmatic pleural thickening (6\%). For calcified pleural changes and for the combination of diffuse pleural thickening and obliteration of the costophrenic angle, false negative reports were absent. The present study shows an unsatisfactory sensitivity for clinical compared with
\end{abstract}

\footnotetext{
Department of Occupational and Environmental Health, Lund University, Lund, Sweden M Albin

The Construction Industry's Organisation for Working Environment, Safety and Health, Stockholm and Gothenburg

G Engholm, K Fröström, L Swantesson

Department of Radiology, Sahlgrenska Hospital $S$ Kheddache

Department of Lung Medicine, Renström's Hospital, Gothenburg

$S$ Larsson
}

ILO readings as a means for screening the parenchyma of workers with a risk of pneumoconiosis.

Workers exposed to fibrogenic dust such as asbestos or quartz are in many countries subject to periodic medical examinations aiming primarily at early detection of pneumoconioses to prevent further potentially deleterious exposure. It also allows the detection of other pulmonary diseases that might make the worker more vulnerable to exposure to dust. Accuracy (sensitivity, specificity) is necessary to achieve these aims. Failure is costly for the worker at risk in terms of impaired health or loss of job and for society in terms of non-optimal allocation of resources for diagnostic procedures and improvement of working conditions. The evaluation of the effectiveness (for protection of health) of current programmes for medical surveillance of workers exposed to asbestos or quartz was recently described as an unresolved issue "that deserves careful scrutiny."'

In Sweden, periodic medical examinations are statutory for workers with appreciable exposure to asbestos or quartz. Consequently, some 4000 construction workers have been examined with chest $x$ ray films each year through the Construction Industry's Organisation for Working Environment, Safety and Health.

Chest $x$ ray films from periodic examinations of construction workers have been read both routinely by a physician (radiologist or chest physician), and in accordance with the ILO (1980) classification ${ }^{2}$ by a panel, to evaluate the present routines. The results are presented here.

\section{Materials and methods}

Chest $x$ ray films from periodic examinations of 6049 construction workers were assessed using the full International Labour Office (ILO) (1980) classification. By extension of the classification, pleural strands (separate, convergent, or forming atelectasis) were coded as additional symbols. The panel consisted of 15 members (lung physicians, specialists in occupational medicine, occupational health doctors, and nurses). During a training session, each member 
of the panel read as many as possible of 450 films, sampled from the total material of construction workers, and was continuously provided with tabulations of his own readings in relation to the ones made by the others. Of the training films, 197 were chosen to be "trigger films".

As well as the mentioned films, 131 films from white collar workers, supposedly unexposed to harmful dusts, were included in the study. These films were all obtained from what will be referred to as geographic area $A$. The films were organised in batches, each containing 100 films plus 10 trigger films. Only posterior-anterior films were read, each batch independently by three readers. For small opacities, individual readers agreed ( \pm 1 subcategory) for 92.6 to $96.6 \%$ of the films compared with the median readings. The individual biasis (overreadingsunderreadings/total readings) ranged from -3.0 to $+5 \cdot 4 \% .^{3}$

All films read as a profusion of small opacities $\geqslant 1 / 2$ by the panel ( $n=34 ; 26$ finally included in our study, see later), have been subject to a special study by Stjernberg and co-workers. One of the cases, an electrician classified as $3 / 3$ by the panel, had, according to the medical records, an advanced sarcoidosis that probably explained his pronounced parenchymal changes (N Stjernberg, personal communication). For the others, no intercurrent diseases could fully explain their parenchymal changes.

Of the 5898 films classifiable for profusion of small opacities (film quality 1 or 2) 258 had a median ILO reading of profusion of small opacities category $\geqslant 1 / 1$. These workers were selected for the present study together with a sample of 258 workers who had a film classified as profusion $<1 / 1$, individually matched for age and geographical area.

The original routine radiological reports were retrieved; 237 cases and 248 referents remained after exclusion of persons in whom the $x$ ray film was taken for reasons other than periodic medical examinations, or when the original radiological report could not be found. Each original radiological report was written by one physician. They were grouped into three geographical areas: region A (239 films), B (106 films), and C (140 films). The films from regions $A$ and $B$ had been assessed by a few physicians (region $A$ usually one out of two), whereas the films from region $\mathrm{C}$ were assessed by several physicians, consequently reading few films each.

The routine radiological reports from the periodic medical examinations were coded in a standardised way for the present study (separately for parenchyma and pleura) as reporting either normal, suspected pathological, or pathological findings. They were further subdivided for the parenchyma as changes classified as pneumoconiosis (including descriptions of changes compatible with pneumoconioses) or as showing findings other than pneumoconiosis. For the pleura, positive findings were grouped as pleural plaques (including suspected ones), other specified pleural changes, or pleural unspecified changes. Radiological reports with no comment on the state of the parenchyma $(n=153)$ or the pleura $(n=182)$ were handled as normal in the analysis.

This coding was performed independently by two investigators (usually one radiologist or chest physician) blinded as to the case or referent state. Discrepancies in the coding between these two were solved through a master reading by two to four of the other investigators. The coded version of the original radiological report was compared with the median ILO reading of the same film. Overweight was estimated by the ponderosity-(Quetelet) index, calculated as weight $(\mathrm{kg}) /($ height $(\mathrm{m})){ }^{2}$ In the processing of the data in this descriptive analysis, tabulations were made disregarding the individual matching of films with profusion $<1 / 1$ and $\geqslant 1 / 1$.

\section{Results}

\section{PARENCHYMAL CHANGES}

In the original radiological reports, $98(41 \%)$ of the films classified as profusion of small opacities $\geqslant 1 / 1$ were recorded as having any type of certain $(27 \%)$ or suspected $(14 \%)$ pathological changes of the parenchyma. The parenchymal changes were described as pneumoconiotic or as showing unspecified parenchymal changes compatible with pneumoconiosis for 56 films.

Of the films classified as $<1 / 1,201(81 \%)$ were classified as normal. Two of the films (with a panel reading of ILO category $0 / 0$ and $1 / 0$ respectively) were described in the original reports as showing parenchymal asbestosis, eight as having unspecified parenchymal changes compatible with pneumoconiosis, none as having silicosis.

A positive association was seen between the proportion of films classified in the routine

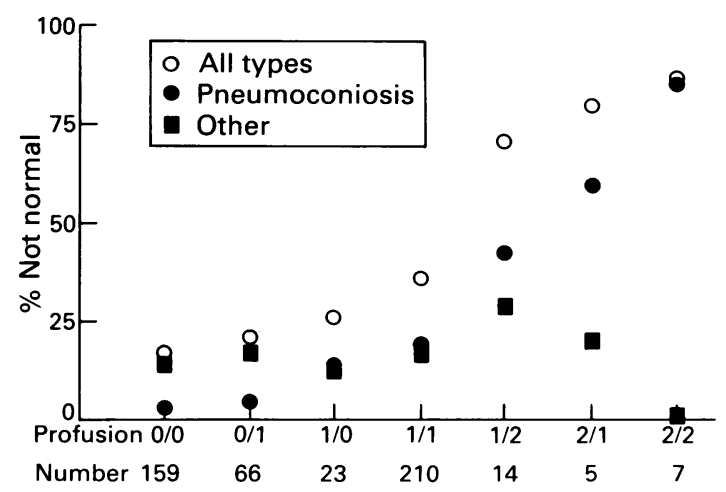

Figure 1 Proportion of films recorded as abnormal in routine radiological reports $v$ the profusion category (ILO 1980) assessed by a panel. 
radiological reports as having any abnormality in the parenchyma and the category of profusion of small opacities according to the ILO classification (fig 1). The association was most striking when only pneumoconiosis (certain or suspected) was considered. The proportion of other disease was roughly constant over the ILO categories.

In the routine readings, only $20 \%(41 / 210)$ in profusion category $1 / 1$ were reported as showing pneumoconiosis. More than half of the films were recorded as any parenchymal abnormality (certain or suspected) only when the ILO reading was profusion category $1 / 2$ or higher ( 26 cases). For pneumoconiosis, the corresponding ILO reading was as high as $2 / 1$ or more ( 12 cases).

The proportion of films with profusion category $\geqslant 1 / 1$ classified as pneumoconiotic (or compatible with pneumoconiosis) varied with type and size of small opacities (232 films classifiable for median type and size). The proportion was much higher for rounded $(7 / 11,64 \%)$, than for irregular $(37 / 192$, $19 \%$ ) opacities, with an intermediate proportion for the ones with both rounded and irregular opacities $(11 / 29,38 \%)$. The fraction increased with the size of the rounded opacities (p 3/11, 27\%; q 12/25, 48\%; $r$ three out of four diagnosed as silicosis, one as sarcoidosis (not in fig)). Among the irregular opacities, there was no such trend (s (smallest) 13/38, $34 \%$; $35 / 183,19 \%$; no median reading of $u$ by the panel). Only one film had a median reading positive for large opacities (type B). It was diagnosed as silicotic in the clinical reading.

Differences were seen between the geographical areas in the extent to which the routine readings agreed with the ILO readings (fig 2). Generally, over the ILO categories, reports from area $A$ had the highest fraction of positive pneumoconiotic findings and area $C$ the lowest.

The sensitivity of the clinical reports, tentatively using the classification by the panel as the "gold standard," was generally low (fig 3 ). The specificity was high.

\section{INFLUENCE BY CONCOMITANT FEATURES}

There was no major difference between films classified as $\geqslant 1 / 1$ and $<1 / 1$ in the proportion of persons with a ponderosity index on the top quartile (index $\geqslant 28: 29$ and $22 \%$ respectively).

The routine readings reported parenchymal features other than pneumoconiosis (tuberculosis, sarcoidosis, cardiac incompensation, chronic obstructive lung disease, poor breath) among profusion categories $\geqslant 1 / 1$ for 51 films $(22 \%)$, and for 42 films $(17 \%)$ in profusion categories $<1 / 1$. Thus these characteristics cannot explain the discrepancies in the reading of pneumoconiosis in the routine $v$ the ILO readings.

\section{PLEURAL CHANGES}

In the total material, $233(48 \%)$ of the films were

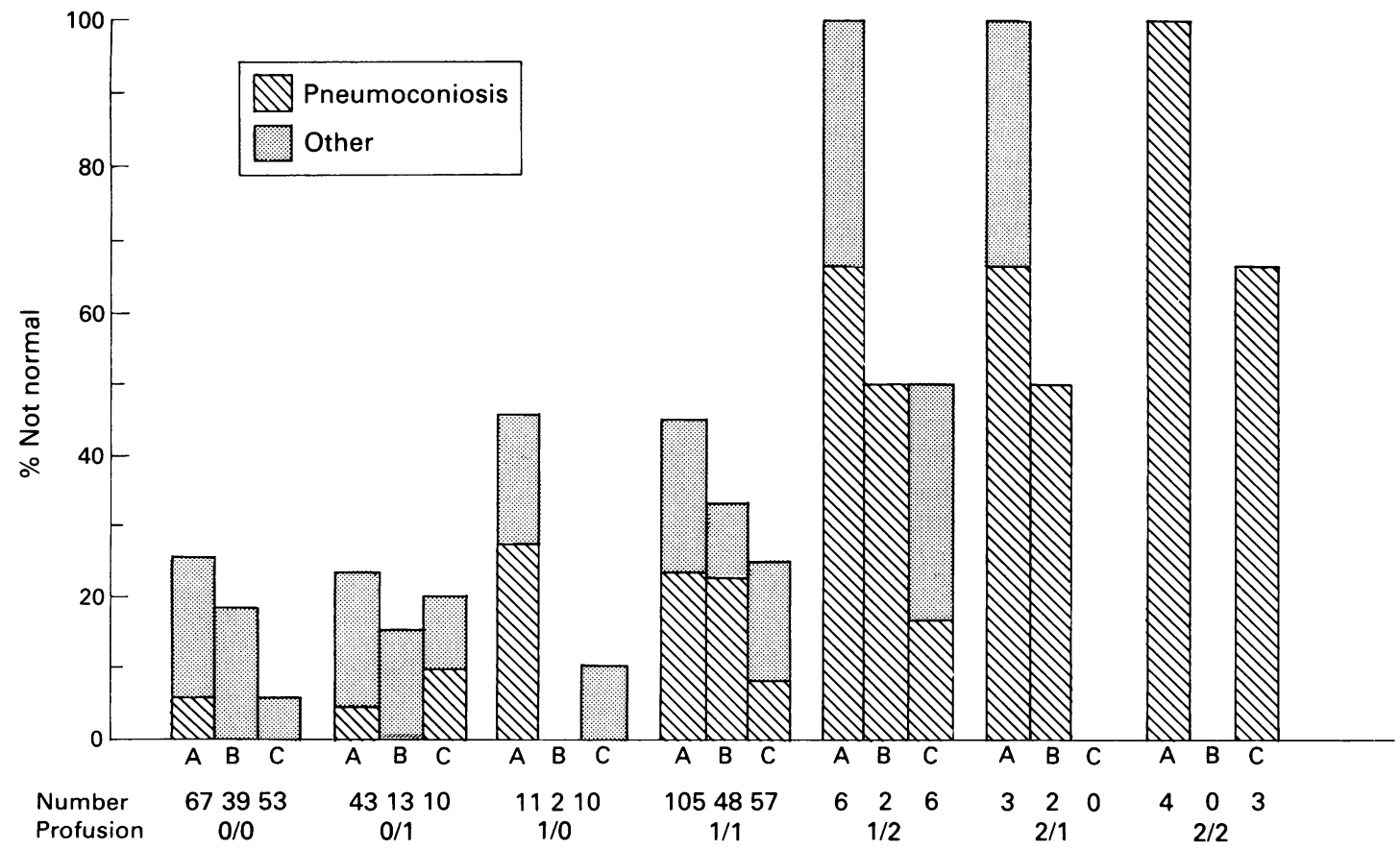

Figure 2 Proportion of films classified as abnormal in three geographical areas $(A, B, C)$ by profusion category. 


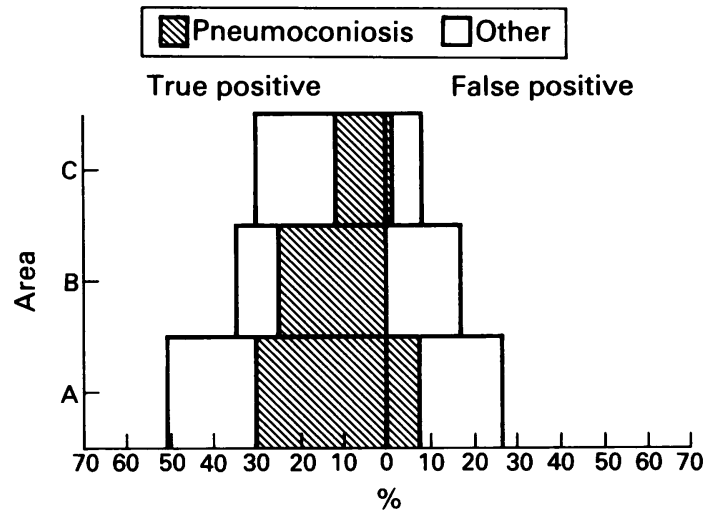

Figure 3 Discrimination between $<1 / 1$ and $\geqslant 1 / 1$ in routine radiological reports using the classification by a panel as a standard.

classified according to ILO (1980) as showing pleural thickening of the chest wall (diffuse or circumscribed) and 66 films $(14 \%)$ pleural thickening of the diaphragm. Generally, a high proportion of these changes was reported in the routine readings (table). Thus a high proportion of films with ILO readings of pleural thickening of the diaphragm were described as showing suspected or definite pleural plaques in the clinical readings (unilateral $43 / 51,84 \%$; bilateral $14 / 15,93 \%$ ); and so was circumscribed pleural thickening of the chest wall (unilateral $34 / 47,72 \%$; bilateral $69 / 77,90 \%$ ).

The proportions of reported pathological or suspected pathological pleural findings for diffuse pleural thickening were $70 \%$ for both unilateral (39/67) and bilateral (32/46) changes. All films with diffuse pleural thickening of the chest wall combined with obliteration of the costophrenic angle (11/11) were reported as having a definite pathological pleura.

The proportion of clinical readings without recorded pleural changes decreased with increasing extent and width of pleural thickening of the chest wall according to the ILO readings (table). Thus all films with pleural thickening width $>10 \mathrm{~mm}$ were reported as definite pleural plaques, compared with half of the films with width $\leqslant 5 \mathrm{~mm}$. All films with pleural calcification $(n=35)$ were reported as definitely pathological, all but one showing definite or suspected pleural plaques. No trends were found between the proportion of false negative reports and Queteletindex for diffuse or circumscribed pleural thickening of the chest wall. Pleural strands (separate, convergent, or forming an atelectasis) were recorded in 24 clinical readings and in 23 readings by the panel (only three concordant positive).

The proportion of films with certain or suspected pathological pleural changes according to the clinical readings was similar among subjects with parenchymal changes $\geqslant 1 / 1$ and $<1 / 1(48 v 45 \%)$. In the ILO readings, pleural thickening of the chest wall was more often recorded for profusion $\geqslant 1 / 1(54 \%)$ than $<1 / 1(42 \%)$, but distributions of width, extent, and type (circumscribed, diffuse) for recorded changes were similar between the two groups.

\section{Discussion}

PARENCHYMA

The proportion of films classified in routine radiological reports as pneumoconiotic, or even as

Relations between ILO and clinical readings for pleural changes in 5898 construction workers

\begin{tabular}{|c|c|c|c|c|}
\hline \multirow[b]{2}{*}{$I L O$ readings } & \multicolumn{4}{|c|}{ Clinical readings of pleura } \\
\hline & $\begin{array}{l}\text { Total } \\
\text { No }\end{array}$ & $\begin{array}{l}\text { Not normal } \\
\text { No }(\%)\end{array}$ & $\begin{array}{l}\text { Suspected plaques } \\
\text { No }(\%)\end{array}$ & $\begin{array}{l}\text { Plaques } \\
\text { No }(\%)\end{array}$ \\
\hline $\begin{array}{l}\text { Pleural thickening: } \\
\text { Diaphragm } \\
\text { Chest wall* }\end{array}$ & 66 & $62(94)$ & $2(3)$ & $55(83)$ \\
\hline $\begin{array}{l}\text { Circumscribed only } \\
\text { Circumscribed and diffuse } \\
\text { Diffuse only }\end{array}$ & $\begin{array}{r}96 \\
5 \\
73\end{array}$ & $\begin{array}{c}87(91) \\
5(100) \\
51(70)\end{array}$ & $\begin{array}{c}6(6) \\
1(20) \\
13(18)\end{array}$ & $\begin{array}{r}76(79) \\
3(60) \\
22(30)\end{array}$ \\
\hline $\begin{array}{l}\text { Extent: } \dagger \\
\quad \leqslant 1 / 4(1) \\
<1 / 4 \text { and } \leqslant 1 / 2(2) \\
>1 / 2(3)\end{array}$ & $\begin{array}{r}96 \\
109 \\
28\end{array}$ & $\begin{array}{l}57(59) \\
93(85) \\
27(96)\end{array}$ & $\begin{array}{r}11(11) \\
14(13) \\
4(14)\end{array}$ & $\begin{array}{l}37(39) \\
65(69) \\
16(57)\end{array}$ \\
\hline $\begin{array}{l}\text { Width: } \dagger \\
\leqslant 5 \mathrm{~mm}(\mathrm{~A}) \\
>5 \text { and } \leqslant 10 \mathrm{~mm}(\mathrm{~B}) \\
>10 \mathrm{~mm}(\mathrm{C})\end{array}$ & $\begin{array}{r}140 \\
79 \\
5\end{array}$ & $\begin{array}{l}92(66) \\
73(92) \\
5(100)\end{array}$ & $\begin{array}{l}20(14) \\
8(10) \\
0\end{array}$ & $\begin{array}{l}50(36) \\
58(73) \\
5(100)\end{array}$ \\
\hline $\begin{array}{l}\text { Pleural calcification: } \\
\text { Chest wall } \\
\text { Diaphragm } \\
\text { Other sites }\end{array}$ & $\begin{array}{r}15 \\
28 \\
2\end{array}$ & $\begin{array}{r}15(100) \\
28(100) \\
2(100)\end{array}$ & $\begin{array}{l}2(13) \\
1(4) \\
0\end{array}$ & $\begin{array}{c}13(87) \\
26(93) \\
2(100)\end{array}$ \\
\hline
\end{tabular}

$\star$ Left side.

† Maximum extent/width of pleural thickening; lateral chest wall, either side. 
having any pathological findings, was low among cases with profusion category $1 / 1$ or more. The proportion of false positive readings was also low.

The relations found indicate that in routine radiological reports, the level for classifying a film as pneumoconiotic or compatible with pneumoconiosis, either suspected or certain, is in fact around ILO category $2 / 1$. A difference existed, however, between different hospitals with one centre, serving area $\mathrm{A}$ generally recording more findings. The differences in proportion of positive clinical readings between the areas probably reflects, at least in part, differences in the number of films read by each radiologist or lung physician.

The differences may, however, also represent different policies in dealing with the problem of false negatives or positives. When subtle changes are more often classified as pathological, the burden on the diagnostic resources will increase, not only from pneumoconiotic subjects, but also healthy ones, who will suffer from "needless fear and perceived incapacity." Our results show that the detection limit in the routine readings was higher than would be desirable.

An increasing sensitivity was found with the size of rounded opacities and the lowest sensitivity was found for irregular ones. A similar finding was made by Gaensler et al. ${ }^{5}$ This might be because irregular opacities with a low profusion category are more nonspecific for dust exposure (increasing with age, ${ }^{6}$ with smoking, ${ }^{78}$ (although contested by Kilburn et $a l^{9}$ ), and ponderosity ${ }^{10}$ ) than the rounded ones. Thus such a conservative reading of films from workers exposed to dust is beneficial in reducing the number of false positive readings, but at the same time potentially dangerous, as it may delay further diagnostic procedures, appropriate removal from further exposure to dust, and general measures to reduce the dust exposure at the workplace. It may still be important to detect irregular opacities, however. Although handling of asbestos is heavily restricted, exposures of concern do remain among several groups, such as asbestos demolition workers, workers exposed to minerals contaminated with tremolite fibres, and possibly also among workers exposed to crystalline fibres other than asbestos. The low sensitivity in the routine readings is in agreement with the findings of an earlier study (30\% false negative readings, pleura and parenchyma). ${ }^{11}$

There was probably no major systematic observation bias in the ILO readings by the panel. Thus in the material from white collar workers assessed by the panel in the original study $11 \%$ had a median reading of $\geqslant 1 / 0$ and $5 \%$ of $\geqslant 1 / 1$. This is within the range of previously published reference populations ( 4 to $18 \%$ in category $\geqslant 1 / 0)^{679}$ Assuming that the films from white collar workers are representative of an unexposed population and that no changes clas- sifiable as small opacities are present in such a population, our results indicate that when dichotomising between $1 / 0$ and $1 / 1$ the proportion of false positive readings by the panel using the ILO classification is roughly $5 \%$. This is close to the commonly used procedures for establishing a normal range in which findings exceeding two standard deviations $(2.5 \%)$ are classified as pathological. An important difference between an ILO reading and a traditional radiological report is that the first is technically descriptive and based on posterioranterior projections only, whereas the second is diagnostic and includes clinical data as well as further projections. Moreover, only six out of 15 members in the panel had had a formal training in thoracic radiology. These differences would all tend to make it more difficult for the panel than for the clinical radiologist to discriminate between pneumoconiotic and non-pneumoconiotic changes.

Analysis of our data, accounting for the possible influence on the readings of parenchymal changes from other concomitant diseases, pleural changes, and overweight, did not explain the differences between the ILO and the routine readings, although slightly higher proportions of these characteristics were found for high profusion categories. Age and film technique might bear upon the reading of small opacities. Age was matched for in sampling films $<1 / 1$ and $\geqslant 1 / 1$, and so was region. Within regions $A$ and $B$, film technique was similar. Thus age and film technique is (roughly) accounted for in comparisons stratified by region, and dichotomised at $1 / 1$, whereas analysis by profusion category could be biased; however, as the results were similar for both types of analyses uneven distributions of age and film technique over profusion categories could not create the discrepancies between the ILO and the clinical readings.

The ILO classification is a useful tool. It was designed mainly for evaluation of effects of exposure to dust in groups of workers in scientific studies, and in occupational health. The classification has also been recommended, however, for use in periodic medical examinations ${ }^{12}$ to select individual workers for whom further diagnostic procedures should be initiated.

We used $1 / 1$ as a cut off between normal subjects and cases (suspected and certain) of pneumoconiosis. This is the action level recommended in Sweden by the National Board of Health and Welfare. ${ }^{13}$ It has been claimed that in current practice an ILO grade of $<1 / 0$ makes asbestosis unlikely, ${ }^{14}$ although $10-16 \%$ of the patients with histopathologically proved fibrosis have been shown to have false negative radiographs. ${ }^{1516}$ In silicosis, the problem with false negative radiographs is less. ${ }^{5}$ Coal miners in the United States are given the option of transfer at an agreed reading of profusion category $\geqslant 1 / 0 .{ }^{17}$ 
PLEURA

There was a reasonably good sensitivity in the routine reports on pleural changes. The proportion of false negative clinical reports was low for circumscribed pleural thickening of the chest wall and diaphragmatic pleural thickening; and virtually absent for calcified pleural changes and the combination of diffuse pleural thickening and obliteration of the costophrenic angle. Only diffuse pleural thickening of the chest wall, without obliteration of the costophrenic angle, and circumscribed changes with minimal width and extent, had $\geqslant 30 \%$ false negatives. This is remarkable, especially when compared with the proportion of false negative readings of parenchymal changes. The good agreement on circumscribed pleural thickening could partly be due to the widely circulated diagnostic criteria for pleural changes (for compensation purposes), initially proposed by Thiringer et al, ${ }^{18}$ and later confirmed in recommendations issued by the National Swedish Board of Health and Welfare (requesting width $\geqslant 5 \mathrm{~mm}$ for chest wall and $\geqslant 3 \mathrm{~mm}$ for diaphragmatic uncalcified pleural thickening). ${ }^{13}$ These criteria are, however, not entirely congruent with the ILO classification.

The high sensitivity for the combination of diffuse pleural thickening and obliteration of the costophrenic angle is especially gratifying, as this type of pleural changes (even without parenchymal fibrosis) is associated with impairment of the lung function. ${ }^{19-22}$

\section{PROPOSALS}

A discussion is warranted on the present procedures in Sweden for periodic medical examinations of workers exposed to fibrogenic dust. Coding of the $x$ ray films according to the ILO classification by trained readers as a complement to the traditional clinical report, would be one possible way to improve the sensitivity in the reading of parenchymal changes.

Temporal certification of readers is employed in the United States to grant sufficient knowledge and uniformity in the use of the classification for surveillance of coal miners. In scientific studies, uniformity and reproducibility in the readings is now optimised by the use of trigger films (films with previously agreed readings) throughout the studies. The use of these techniques and a centralisation to a few centres of the readings are possibilities to compensate for the decreasing amount of films with pneumoconiotic changes encountered by the general lung physician or radiologist.

Another possibility to improve the diagnostics is high resolution computed tomography, which has been shown to correlate rather well with histopathologically proved asbestos disease, ${ }^{23}$ to detect early silicotic changes, and to reduce interreader variability. ${ }^{24} \mathrm{~A}$ scoring system for asbestos related disease has recently been suggested..$^{25} \mathrm{High}$ resolution computed tomography is, however, presently available for routine examination only at a few centres, and the dose of ionising radiation is higher than with standard techniques. Thus, systematic use of the ILO classification in the surveillance of workers exposed to fibrogenic dust is still to be recommended.

\section{Addendum}

After we submitted this paper for publication, Hilt and co-workers published a paper in which 430 radiographs clinically recorded as showing asbestos related parenchymal or pleural abnormalities, were reassessed using the ILO classification. As in our study, they found a low sensitivity for parenchymal, and a high sensitivity for pleural, changes in the clinical readings. Contrary to our findings, the specificity in the clinical readings of parenchymal abnormalities, was also low (Hilt B, Borgersen A, Lien JT, Langård $\mathrm{S}$. Chest radiographs in subjects with asbestos-related abnormalities: comparison between ILO categorisations and clinical reading. $A m \mathrm{~J}$ Ind Med 1992;21:855-61).

The ILO readings were carried out by us (except $\mathrm{GE}$ ), and by Håkan Arvidsson $\mathrm{MD}$, Bengt Fristedt MD, Ebba Granqvist, registered nurse, Gunnar Hillerdal MD, Kristina Jakobsson MD, Gerd Lindén, registered nurse, Berit Salomon MD, Nils Stjernberg MD, Jan Tollqvist $\mathrm{MD}$ and Göran Tornling MD. The panel was trained by Charles E Rossiter MA, DSc(Med), FFOM. Zoli Mikoczy BSc produced the graphs. The trial was initiated by Anders Englund MD of the Construction Industry's Organization for Working Environment, Safety and Health, and supported by a grant from the Swedish Work Environment Fund (AMF 596/88). This is gratefully acknowledged.

Requests for reprints to: Maria Albin, Department of Occupational and Environmental Medicine, University Hospital, S-221 85 Lund, Sweden.

1 Becklake MR. Evaluation of respiratory hazards in the working environment through environmental, epidemiological and medical surveys. In: Proceedings of the VIIth international pneumoconioses conference, Pittsburgh, 1988. Part 1, 1990; 16-22. (DHHS (NIOSH publ No 90-108.)

2 International Labour Office. Guidelines for the use of ILO international classification of radiographs of pneumoconioses. Geneva: ILO, 1980 (Occupational safety and health series: No 22).

3 Rossiter CE, Stjernberg N, Lindén G, Englund A. Bygghälsan study of construction workers exposed to silica dust and/or asbestos: chest $x$-ray reading trials. 23rd International congress on occupational health of the international commission on occupational health, ICOH, Montréal, 1990. Book of abstracts 1990; 251.

4 Weill H. Diagnosis of asbestos-related disease. Chest 1987;91: 802-3.

5 Gaensler EA, Carrington CB, Couto RE, Tomasian A, Hoffman L, Smith AA. Pathological, physiological, and radiological 
correlations in the pneumoconioses. Ann NY Acad Sci 1972;200:572-607.

6 Epstein DM, Miller WT, Bresnitz EA, Levine MS, Gefter WB. Application of IILO classification to a population without industrial exposure: findings to be differentiated from pneumoconiosis. AmJ Roentgenol 1984;142:53-8.

7 Weiss W. Smoking and pulmonary fibrosis. J Occup Med 1988;30:33-9.

8 Weiss W. Cigarette smoking and small irregular opacities. $\mathrm{Br} J$ Ind Med 1991;48:841-4

9 Kilburn KH, Lilis R, Anderson HA, Miller A, Warshaw RH. Interaction of asbestos, age and cigarette smoking in producing radiographic evidence of diffuse pulmonary fibrosis. $\mathrm{Am} \mathrm{J}$ Med 1986;80:377-81.

10 Stjernberg N, Rossiter CE, Englund A. Effect of body mass on radiographic appearances. 23rd international congress on occupational health of the international commission on occupational health, ICOH, Montréal, 1990. Book of abstracts 1990; 272.

11 Sheers G, Rossiter CE, Gilson JC, Mackenzie FAF. UK naval dockyards asbestosis study: radiological methods in the surveillance of workers exposed to asbestos. $\mathrm{Br} J$ Ind $\mathrm{Med}$ 1978;35:195-203.

12 International Labour Office. Safety in the use of asbestos: An ILO code of practice. Geneva: ILO, 1984.

13 Diagnostik av dammlunga förorsakad av kvarts och asbest. Allmänna rad från Socialstyrelsen 1987:4, Stockholm 1987. (In Swedish.)

14 Gefter WB, Conant EF. Issues and controversies in the plainfilm diagnosis of asbestos-related disorders in the chest. $J$ Thorac Imaging 1988;3:11-28.

15 Epler GR, McLoud TC, Gaensler EA, Mikus JP, Carrington CB. Normal chest roentgenograms in chronic diffuse infiltrative lung disease. $N$ Engl J Med 1978;298:934-9.
16 Gaensler EA, Carrington CB. Open biopsy for chronic diffuse infiltrative lung disease: Clinical, roentgenographic, and physiologic correlations in 502 patients. Ann Thorac Surg 1980;30:411-26.

17 Federal Register 1979;44(76):23084-5.

18 Thiringer G, Blomqvist N, Brolin I, Mattsson SB. Pleural plaques in chest $x$-rays of lung cancer patients and matched controls (Preliminary results). Eur J Respir Dis 1980;61 (supp 107):119-22.

19 Wright PH, Hanson A, Kreel L, Capel LH. Respiratory function after asbestos pleurisy. Thorax 1980;35:31-6.

20 McLoud TC, Woods BO, Carrington CB, Epler GR, Gaensler EA. Diffuse pleural thickening in an asbestos-exposed population: prevalence and causes. Am J Roentgenol 1985;144:9-18.

21 Hillerdal G, Malmberg P, Hemmingsson A. Asbestos-related lesions of the pleura: parietal plaques compared to diffuse thickening studied with chest roentgenography, computed tomography, lung function, and gas exchange. Am J Ind Med 1990;18:627-39.

22 Kouris SP, Parker DL, Bender AP, Williams AN. Effects of asbestos-related pleural disease on pulmonary function. Scand $J$ Work Environ Health 1991;17:179-83.

23 Akira M, Yamamoto S, Yokoyama K, Kita N, Morinaga K, Higashihara T, Kozuka T. Asbestosis: high-resolution CTpathologic correlation. Radiology 1990;176:389-94.

24 Bégin R, Ostiguy G, Fillion R, Colman N. Computed tomography scan in the early detection of silicosis. Am Rev Respir Dis 1991;144:697-705.

25 Al Jarad N, Wilkinson P, Pearson MC, Rudd RM. A new high resolution computed tomography scoring system for pulmonary fibrosis, pleural disease, and emphysema in patients with asbestos related disease. $\mathrm{Br} J$ Ind Med 1992;49:73-84.

Accepted 16 March 1992 